кандидат политических наук, доцент кафедры социологии филиала Российского государственного социального университета в г. Пятигорске

\section{МОЛОДЕЖНАЯ ОРГАНИЗАЦИЯ КАК ОСНОВНОЙ ЭЛЕМЕНТ СТРУКТУРЫ МОЛОДЕЖНОЙ ПОЛИТИКИ В РОССИИ}

Аннотация:

В статье рассматривается вопрос формирования и реализации системы молодежной политики в России. Делается вывод о необходимости активного взаимодействия в этой сфере государства и институтов гражданского общества в рамках молодежной организации, обладающей реальными полномочиями и возможностями решения молодежных проблем.

Ключевые слова:

молодежь, воздействие, государство, государственная молодежная политика, молодежная организация, функции, проблемы, эффективность, институты.
PhD in Political Science, Assistant Professor Social Science Department Pyatigorsk branch of Russian State Social University

\section{YOUTH ORGANIZATION AS THE BASIC ELEMENT OF THE YOUTH POLICY STRUCTURE IN RUSSIA}

Summary:

The article examines the issue of formation and implementation of the youth policy system in Russia. The author concludes about the need for active cooperation between the state and the civil society institutions in this field in the context of the youth organization having real powers and opportunities to solve the youth problems.

Keywords:

youth, impact, state, state youth policy, youth organization, functions, problems, efficiency, institutions.

Анализ различных подходов к формированию и реализации молодежной политики в России, изучение системы государственной молодежной политики СССР и Российской Федерации, оценка результатов исследований в данной области позволяют говорить о возможности повышения эффективности отечественной молодежной политики путем создания национальной молодежной организации. Анализ функционирования единственной общенациональной молодежной организации свидетельствует о наличии в российской истории опыта системной работы с молодежью. Подобный опыт, разумеется с учетом современных особенностей развития общества и государства, целесообразно использовать при совершенствовании отечественной системы молодежной политики.

В силу известных социально-политических причин создание аналога ВЛКСМ в современном российском обществе невозможно. Тем не менее изучение подходов к реализации молодежной политики в СССР и России, а также анализ исследований в этой сфере позволяют выявить основные черты структуры и системы функционирования такой организации [1, с. 125; 2, с. 78].

Анализ деятельности ВЛКСМ показывает, что комсомол, официально являясь помощником и резервом правящей партии, конечно, создавался и функционировал в ее интересах. Задачи и цели партии декларировались в соответствии с интересами общества и народа. Таким образом, комсомол, по словам В.К. Криворученко, «был включен в решение общенародных задач»: руководство страны через структуру данной организации осуществляло идеологическое воспитание молодежи, реализовывало политические и социальные проекты; более того, ВЛКСМ позиционировался как «помощник и резерв» КПСС, то есть являлся полноценной и достаточно самостоятельной частью управления страной. Под непосредственным руководством комсомола было создано детское политическое объединение Всероссийская (Всесоюзная) пионерская организация имени В.И. Ленина.

Таким образом, комсомол, то есть государственная молодежная организация, являлся краеугольным камнем государственной молодежной политики руководства страны. В обязанности данного объединения входил активный и профессиональный охват всех вопросов, касающихся молодежи в СССР: формирования системы ценностей; выбора жизненного пути; трудоустройства; получения образования; выполнения поставленных партией задач по восстановлению народного хозяйства, а затем и его развитию; культуры; подготовки руководящих кадров и т. д. ВЛКСМ имел самостоятельность, широкие полномочия и возможности влияния практически на все процессы в обществе. Это позволяло организации активно и эффективно способствовать объединению усилий всех общественных подсистем в деле решения проблем молодежи. Совокупность данных аспектов позволяла проводить эффективную государственную молодежную политику в СССР.

Тем не менее в поздний период существования СССР членство в ВЛКСМ по сути стало обязательным для построения и реализации успешной карьеры для всех представителей молодежи в СССР. Организация объединяла в своих рядах большинство молодых людей, расширяя 
социальную базу. В 1960-1980-е гг. прием в комсомол стал традиционным практически для всех старшеклассников общеобразовательных школ, что привело к потере структурной четкости. Членство в ВЛКСМ воспринималось как естественный для молодого человека шаг, следующий после пионерской организации, этап взросления, не связанный с социально-политическим развитием. Комсомол повторил путь КПСС, став составной частью бюрократической системы, сформировавшейся в СССР на последнем этапе его существования.

Поэтому можно говорить о том, что от комсомола формируемой молодежной организации следует воспринять прежде всего системность, степень самостоятельности и масштаб полномочий. При этом официальное членство в данном объединении не должно являться обязательным условием для оказания помощи в решении проблем конкретного представителя молодежи. Расширение сети организации, охват регионов и населенных пунктов должны быть одной из главных целей, способствуя оказанию помощи максимально большему количеству молодых людей. Однако это должно происходить не за счет увеличения количества членов организации, а с помощью создания ее новых отделений и их эффективной работы.

Такие ученые и специалисты в сфере молодежной политики в России, как В.К. Криворученко, Л.А. Рахимова, И.М. Ильинский, В.А. Луков, наряду с решающей ролью государства в данной области с разной степенью значимости выделяют участие институтов гражданского общества, отличая их деятельность в отношении молодежной политики от деятельности государства в этой сорере [3]. Исследования позволяют говорить о том, что в настоящее время ситуация не изменилась: и молодежь, и эксперты выступают за то, что молодежная политика не должна быть лишь государственной прерогативой [4, с. 122]. Ее разработка и осуществление должны быть делом всех социальных институтов. Принято выделять два вида молодежной политики [5, с. 137].

В качестве первого вида выступает государственная молодежная политика, осуществляемая государством, делегирующим основную роль специальным органам. Деятельность последних связана с культурой, образованием, трудом, ффизическим развитием, досугом - то есть с развитием человека. Государственная молодежная политика может в качестве основы иметь определенную идеологию и систему права. Чаще всего это позволяет очертить базовые параметры идеального проекта (образа) молодого человека и молодежи, отвечающего с точки зрения государства вызовам истории и потребностям совершенствования человека и общества.

В качестве второго вида принято выделять общественную молодежную политику, когда главные функции осуществляют социальные организации - профсоюзы, разные партии, СМИ, бизнес-сообщества, молодежные объединения, а также сама молодежь. При этом общественные силы могут планировать и реализовывать молодежную политику на основе собственных ресурсов. Молодежная политика политических партий, общественных объединений вносит существенный, возможно, определяющий вклад в выработку той самой идеальной для социума модели молодого человека, но уже с общественных позиций. Отсюда представляется оптимальным тесное сотрудничество государства и общественных организаций в планировании и реализации молодежной политики.

Также можно говорить о том, что формирование системы ценностных ориентаций является основной составляющей молодежной политики. Именно здесь должны быть сконцентрированы усилия институтов гражданского общества в рамках молодежной политики, а государства - в области нормативного закрепления этой системы ценностных ориентаций. Отсюда в целях эффективности работы становится очевидной необходимость совместных и скоординированных усилий на единой площадке, определяемых едиными рамками и принципами совместной работы. Таким образом, данная деятельность может осуществляться в рамках единой молодежной организации, функционирующей на основе межинституционального взаимодействия.

Между тем исследование нормативной базы в области молодежной политики, методики и результатов работы государственных организаций свидетельствует о неэффрективности их деятельности в данном направлении. Однако анализ показывает, что работа общественных организаций в сфере молодежной политики в большей степени обеспечивает их собственные интересы.

С одной стороны, в данной ситуации сложно рассчитывать на продуктивное взаимодействие двух участников процесса, деятельность которых в рассматриваемой сфрере по отдельности неэффективна. Однако, с другой стороны, специалисты отмечают необходимость совместных действий государственных и общественных институтов, без которых невозможны формирование и реализация эффективной молодежной политики [6].

Постоянно отмечается необходимость привлечения к указанной деятельности молодежи, прежде всего в лице молодежных организаций и других институтов гражданского общества: некоммерческих объединений молодых людей, молодежных палат при органах власти, региональных и муниципальных общественных палат и т. д. При этом чиновники не должны обладать монополией на ее фрормирование и внедрение [7]. Об этом говорит и зарубежный опыт - в европейских странах серьезную роль отводят молодежным организациям [8] 
Институты гражданского общества имеют достаточно широкие ресурсы для эффрективной деятельности в области создания позитивных систем ценностных ориентаций молодежи, а следовательно, для разработки и реализации молодежной политики. Такая деятельность может быть направлена на формирование гражданского облика молодого человека как социальной ценности. При этом институты гражданского общества, входящие в систему молодежной политики в стране, должны, с одной стороны, иметь четкую структуру, цели, определенные рамки деятельности и предполагать в качестве важной составляющей собственной деятельности работу с молодежью; с другой стороны - отдавать приоритет реальным требованиям государства и общества, а не собственным интересам.

Отсюда возникает потребность в выработке оптимальных механизмов взаимосвязи, вопервых, между всеми государственными институтами в области молодежной политики; во-вторых, между институтами гражданского общества; в-третьих, между теми и другими. Такое взаимодействие может быть эффективным в рамках национальной молодежной организации.

\section{Ссылки:}

1. Коряковцева О.А. Государственная молодежная политика в современной России // Вестник Волгоградского государственного университета. Сер. 4. История. Религиоведение. Международные отношения. 2009. № 1 (15). С. $122-129$.

2. Криворученко В.К. Молодежная политика: взгляд ученого и практика // Знание. Понимание. Умение. 2013. № 2. С. 78-87.

3. Луков В.А. Теории молодежи: пути развития // Там же. 2007. № 3. С. 70-82 ; № 4. С. 87-98.

4. Коряковцева О.А. Указ. соч. С. 122.

5. Чирун С.Н. Молодежная политика России в современном методологическом дискурсе // Вестник Поволжского института управления. 2009. № 4. С. 136-139.

6. Скробов А.П. Молодежь России: тенденции социального развития в условиях кризиса. СПб., 2000. 120 с.

7. Елишев С.О. Формирование ценностных ориентаций современной молодежи посредством государственной молодежной политики [Электронный ресурc]. URL: http://ruskline.ru/analitika/2010/05/19/formirovanie_cennostnyh_orientacij_sovremennoj molodyozhi posredstvom gosudarstvennoj_molodyozhnoj_politiki/ (дата обращения: 16.04.2017).

8. Shild $\mathrm{H}$. Start of a new phase in the partnership between the European Union and the Council of Europe in the youth sector // Forum 21: European Journal on Youth Policy. 2007. No. 9.

\section{References}

Chirun, SN 2009, 'Russia's youth policy in contemporary methodological discourse', Vestnik Povolzhskogo instituta upravleniya, no. 4, pp. 136-139, (in Russian). 2017,

Elishev, SO 2017, The formation of value orientations among modern youth through the state youth policy, viewed 16 April lodyozhi posredstvom gosudarstvennoj molodyozhnoj politiki/>, (in Russian).

Koryakovtseva, OA 2009, 'State youth policy in modern Russia', Vestnik Volgogradskogo gosudarstvennogo universiteta. Ser. 4. Istoriya. Religiovedeniye. Mezhdunarodnyye otnosheniya, no. 1 (15), pp. 122-129, (in Russian).

Krivoruchenko, VK 2013, 'Youth policy: the scientist's view and practice', Znaniye. Ponimaniye. Umeniye, no. 2, pp. 78-87, (in Russian).'

Lukov, VA 2007, 'Theories of youth: ways of development', Znaniye. Ponimaniye. Umeniye, no. 3, pp. 70-82, no. 4, pp. 8798, (in Russian).

Shild, H 2007, 'Start of a new phase in the partnership between the European Union and the Council of Europe in the youth sector', Forum 21: European Journal on Youth Policy, no. 9.

Skrobov, AP 2000, Youth of Russia: trends of social development in a crisis, St.-Petersburg, p. 120, (in Russian). 